\title{
O ambiente como questão sociológica: conflitos ambien- tais em perspectiva
}

\author{
LORENA CÂNDIDO FLEURY \\ JALCIONE ALMEIDA" \\ ADRIANO PREMEBIDA
}

\section{Resumo}

Este artigo tem por objetivo contextualizar a concepção de ambiente como domínio de análise sociológica, com vistas a situar os conflitos ambientais como um de seus importantes desdobramentos. Para tanto, será apresentada inicialmente uma revisão de autores e pesquisas em sociologia ambiental com seus distintos enfoques, acompanhada da consideração de outras áreas da sociologia que se debruçaram sobre a relação sociedade-natureza no cenário internacional. Em seguida, será discutido como no Brasil este debate vem sendo realizado e com quais particularidades, direcionando a centralidade do enfoque para o debate acadêmico em torno do conceito de conflitos ambientais.

Palavras-chave: Sociologia ambiental. Conflitos ambientais. Questão ambiental no Brasil.

\footnotetext{
* Universidade Federal do Rio Grande do Sul (UFRGS), Porto Alegre, Rio Grande do Sul, Brasil.

** Universidade Federal do Rio Grande do Sul (UFRGS), Porto Alegre, Rio Grande do Sul, Brasil.

${ }^{* * *}$ Fundação Amazônica de Defesa da Biosfera (FDB), Manaus, Amazonas, Brasil.
} 


\title{
The environment as a sociological issue: environmental conflicts in perspective
}

\begin{abstract}
This article aims to contextualize the notion of environment as an area of sociological analysis, in order to understand the environmental conflicts as one of its main developments. To this end, at first it will be presented a review of environmental sociology studies comprising distinct approaches, also considering other areas of sociology which have examined the relationship between society and nature in the international arena. Then, the text will discuss how this debate is being conducted in Brazil, showing its peculiarities and focusing on the academic debate around the concept of environmental conflicts.
\end{abstract}

Keywords: Environmental sociology. Environmental conflicts. Environmental issue in Brazil.

\section{Introdução}

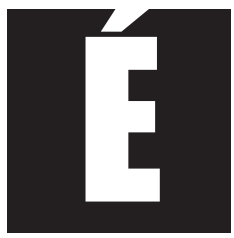

de apenas algumas poucas décadas para o presente que o ambiente tem sido construído como objeto epistêmi$\mathrm{CO}$, e identificado como tema concernente às pesquisas em ciências sociais e particularmente na sociologia ${ }^{1}$. Pressupõe-se que seu surgimento como campo de estudos desta disciplina está vinculado a um processo de demanda por análises teóricas capazes de articular o social e o natural, podendo-se

\footnotetext{
${ }^{1}$ De um modo geral, entende-se por ambiente o conjunto de meios naturais ou artificializados da ecosfera onde os seres humanos se instalaram, que exploram e administram, e o conjunto dos meios não antropizados necessários à sua sobrevivência. Estes meios são caracterizados a) por sua geometria, seus componentes físicos, químicos, biológicos e humanos e a distribuição espacial destes componentes; b) pelos processos de transformação, de ação ou de interação implicando estes componentes, fazendo-os mudar no espaço e no tempo; e c) por suas múltiplas dependências em relação às ações humanas (Jollivet; Pavé, 1993).
} 
identificar na constituição daquela que se convencionou chamar de sociologia ambiental um de seus primeiros acolhimentos. Contudo, pouco a pouco distintas áreas da sociologia começaram a incorporar temáticas ambientais em suas problematizações, compondo um amplo leque de interpretações sobre as interfaces entre sociologia e ambiente.

Este artigo tem por objetivo contextualizar essa concepção do ambiente como domínio de análise sociológica, com vistas a situar os conflitos ambientais como um de seus desdobramentos. Para tanto, será apresentada inicialmente uma revisão de autores e pesquisas em sociologia ambiental com seus distintos enfoques, acompanhada da consideração de outras áreas da sociologia que se debruçaram sobre a relação sociedade-natureza no cenário internacional. Em seguida, será discutido como no Brasil este debate vem sendo realizado e com quais particularidades, o que, finalmente, direcionará a centralidade do enfoque para o debate acadêmico em torno do conceito de conflitos ambientais.

\section{As relações sociedade-natureza em pauta: a emergência da sociologia ambiental}

Intimamente relacionada com a proeminência da questão ambiental$^{2}$ no debate público, a sociologia ambiental começa a delinear seus

\footnotetext{
${ }^{2}$ A configuração do ambiente como uma verdadeira "questão" já subentende a consideração não apenas dos problemas ambientais decorrentes da intensificação do modelo urbano-industrial de desenvolvimento, mas também o debate político e institucionalizado acerca desses problemas. (Gerhardt; Almeida, 2005). Essa questão configura-se como uma interrogação institucionalizada que mobiliza e organiza as representações coletivas. A criação de ministérios públicos do meio ambiente consagra a "questão ambiental" como tema inserido no "espaço público". Algumas evidências podem ser apresentadas de imediato: a) o ambiente como trunfo político, entrando no jogo institucional da democracia regido pelo voto e pelos partidos; b) o lobby ecologista; e c) a construção de uma "opinião pública" cada vez mais sensibilizada pelos problemas ambientais (por exemplo, a exploração de situações locais e em nível regional de conflitos para mostrar a legitimidade das posições ecologistas). (Jollivet; Pavé, 1993; Almeida, 2002).
} 
contornos no início da década de 1970. Hannigan (1997) considera como marco o movimento Earth Day 1970, que reuniu milhões de participantes e, à época, foi interpretado como o "dia primeiro" do ambientalismo 3 . De acordo com este autor, esse evento seria o ponto de partida para a "inauguração do decênio ambiental", a partir do qual os sociólogos se depararam com a circunstância de não ter nenhum corpo teórico ou investigação para os guiar no sentido de uma interpretação particularizada da relação entre a sociedade e a natureza. (Hannigan, 1997, p. 15). Isso se deveria ao fato de os pioneiros sociológicos clássicos, Karl Marx, Max Weber e Émile Durkheim terem deixado um legado fortemente antropocêntrico, incorporado constitutivamente à sociologia moderna.

Nessa mesma linha de interpretação, Mattedi (2003), ao analisar as contribuições dos três autores clássicos, considera que a preocupação dos sociólogos com a relação sociedade-natureza reduzia-se ao modo como as sociedades tradicionais haviam sido limitadas pelo natural, em contraposição às sociedades modernas, que, nestas interpretações, teriam conseguido superar alguns dos limites naturais. Nesse sentido, a sociologia ambiental poderia ser considerada uma crítica aos fundadores da sociologia pela falta de atenção às bases materiais biofísicas da existência humana. (Buttel; Humphrey, 1982).

Constituída, portanto, a partir do objetivo de resgatar a materialidade às análises sociológicas, está na raiz da sociologia ambiental a constatação de que sociedade e natureza devem ser analisadas de forma interligada. No entanto, um de seus principais expoentes, Frederick Buttel, define como objeto de estudo da sociologia ambiental "os valores culturais e crenças que motivam as pessoas a usarem o meio ambiente num sentido particular, e suas eventuais implicações para o consenso

${ }^{3}$ Outros eventos importantes nesta época foram o Clube de Roma e seu relatório Meadows (1972) e a Conferência da ONU, em Estocolmo (1972). 
e o conflito social". (Buttel; Humphrey, 1982, p. 4, destaques nossos). Percebe-se, então, que há um realismo premente nesta concepção da relação sociedade-natureza, em que o ambiente é uno e está situado fora das sociedades para ser usado, de forma particular, pelas sociedades em diferentes contextos históricos e/ou culturais. Buttel destaca ainda uma condição ambivalente do ser humano, como ser biológico e social, o que causaria uma também ambivalência entre a biologia e a sociologia como disciplinas para se estudar o humano em sua ecologia e sociabilidade. (Buttel, 1992, p. 70) ${ }^{4}$.

A forte influência do movimento ambientalista e ecologista para a emergência da sociologia ambiental - seja tendo-o como objeto de estudo, seja como fonte de motivação para a temática ambiental a partir do engajamento pessoal de alguns sociólogos - legou para este campo a assertiva de que a relação sociedade-natureza tende ao desequilíbrio e a uma ruptura ecológica resultante da expansão econômica, além da ênfase no papel da percepção humana sobre o ambiente em decorrência dos dilemas ecológicos das nações industriais avançadas. (Buttel, 1992). Dessas premissas comuns desdobram-se diferentes abordagens no interior da sociologia ambiental (Catton; Dunlap, 1980; Schnaiberg, 1980; Buttel, 1992, entre outros), as quais Mattedi (2003) interpreta como diferentes estratégias de recepção epistemológica que variam, segundo o autor, entre o movimento de redefinição do estatuto disciplinar e o movimento de acomodação à tradição disciplinar. Como representantes do primeiro estão os trabalhos dos sociólogos rurais norte-americanos Catton e Dunlap (1980), que ao final dos anos de 1970 propuseram uma mudança paradigmática para a disciplina acadêmica, criticando o antropocentrismo do pensamento sociológico que se distanciou da variável ambiental, ignoran-

\footnotetext{
${ }^{4}$ Ambivalência esta que marcou a própria fundação da sociologia como ciência.
} 
do que esta influencia diretamente as demais variáveis já contempladas pela sociologia ${ }^{5}$.

Catton e Dunlap (1980) propunham uma separação da sociologia entre dois grandes paradigmas, cujo ponto de corte seria a centralidade do ambiente na análise. Esse modelo ficou conhecido como HEP/NEP, a partir das siglas em inglês de Paradigma da Excepcionalidade Humana (Human Exemptionality Paradigm) e Novo Paradigma Ecológico (New Ecological Paradigm). O primeiro paradigma se caracterizaria pelas premissas de que a) o ser humano é uma criatura singular, pois tem uma cultura; b) a cultura pode variar quase que infinitamente e pode mudar muito mais rápido que as características biológicas; e c) a acumulação cultural significa que o progresso pode continuar sem limites, possibilitando a solução de todos os problemas sociais. Já o segundo paradigma defendido pelos autores sustentava que a) os seres humanos são apenas uma das muitas espécies que de maneira interdependente estão envolvidas nas comunidades bióticas que moldam nossa vida social; b) as complexas ligações entre causa e efeito e o feedback na trama da natureza (web of life) produzem muitas consequências não voluntárias a partir da ação social intencional; e c) o mundo é finito, existindo assim limites potenciais físicos e biológicos que reprimem o crescimento econômico, o progresso social e outros fenômenos da sociedade. (Catton; Dunlap, 1980).

Para comprovar a influência objetiva das mudanças ambientais sobre os valores e atitudes dos indivíduos, os proponentes do NEP aplicaram surveys de opinião pública nos Estados Unidos entre as décadas de 1970 e 1980. No entanto, os autores não deixaram claro como tratar analiticamente essas diferenças de posicionamento. Assim, considerou-se que as premissas do NEP se encontravam num nível de abstração muito elevado

\footnotetext{
${ }^{5}$ Ressalta-se aqui a similaridade não causal com o ideário ambientalista/ecologista em geral, em suas críticas ao antropocentrismo também generalizado em todas as formas de atuação e de conhecimento humanos.
} 
para permitir uma pesquisa significativa, e que alguns dos seus trabalhos se constituem como um conjunto de crenças cognitivas expressas por ativistas ambientalistas e por segmentos do público em geral. (Buttel, 1992, p. 81). E, dessa forma, a difusão de um paradigma ecológico na sociologia não se concretizou. (Buttel, 1996; Dunlap, 1997; Alonso; Costa, 2002).

Em reação às implicações epistemológicas, suscitadas pela tentativa de redefinição do campo disciplinar proposta por Catton e Dunlap, foi formulada uma segunda estratégia de recepção epistemológica, que se caracteriza pela revisão das teorias sociológicas visando extrair subsídios para a interpretação da problemática ambiental. A revisão seguiu em duas direções: o primeiro eixo compreende a retomada das compreensões de Marx, Weber e Durkheim para a análise dos diversos aspectos da questão ambiental. Entre os principais defensores dessa perspectiva estão Alan Schnaiberg e James O'Connor, mediante o programa empreendido pelo que se convencionou chamar de "marxismo ambiental". Schnaiberg (1980) defendeu a tese da contradição entre expansão econômica e equilíbrio ecológico, sintetizada no conceito de rotina da produção (treadmill of production). Haveria uma dialética, uma contradição entre o ecossistema (ambiente natural) e a sociedade humana, que têm diferentes dinâmicas: de um lado, o "moinho da produção" e sua expansão econômica, as relações de produção intensivas em capital deslocando o trabalho e, de outro, a disrupção ambiental que resulta destes imperativos contraditórios mal enfrentados pelo Estado e que levam a uma síntese de escassez planejada. ${ }^{6}$ Já O'Connor (1994) acrescentou ao esquema marxista a natureza como uma terceira categoria, tão importante quanto as de capital e trabalho. No entanto, as críticas a esse programa consideram insuficiente atri-

\footnotetext{
$\overline{{ }^{6} \text { Outros expoentes }}$ desta vertente, mais propriamente da Ecologia Política e não da sociologia ambiental, são André Gorz, Herbert Marcuse, Sicco Mansholt, Alain Bihr e Jean-Pierre Garnier, entre outros.
} 
buir os problemas ambientais à lógica do capitalismo, o que ignoraria que o socialismo também os gerou, e chamam a atenção para o caráter mais normativo que analítico do marxismo ecológico. (Alonso; Costa, 2002).

O segundo eixo de interpretação caracteriza-se pela tentativa de subordinar a análise dos problemas ambientais às estratégias convencionais de abordagem empregadas para o entendimento de outros problemas sociológicos. Este eixo de interpretação agrupa muitos matizes, como por exemplo os conceitos de sociedade de risco (Beck, 1992) e de modernização ecológica (Mol; Spaargaren, 1993), e orientou, a partir dos anos 1990, o que Mattedi (2003, p. 03) analisa como uma renovação no debate sociológico, conformando uma guinada ambiental na sociologia. Nessa "guinada", alguns teóricos não identificados com a sociologia ambiental, como Giddens (1995) e Beck (1992), passaram a dar importância a questões ecológicas e relações socioambientais. (Buttel et al., 1995).

Beck $(1992 ;$ 1995) substitui a ideia de ordem social pela de risco sistêmico. Afirma que no novo padrão reflexivo de modernização o paradigma da escassez (lógica de produção de riquezas da sociedade industrial) estaria sendo substituído pelo paradigma do risco. Os resíduos do processo produtivo estariam crescendo numa expropriação ecológica do estoque planetário de alimentos, ar e água, gerando e difundindo novos riscos objetivos (químicos, nucleares, biogenéticos) que seriam produzidos industrialmente, externalizados economicamente, individualizados juridicamente, legitimados cientificamente e minimizados politicamente. Nesta sociedade (industrial) de risco, os problemas ambientais teriam escala global e consequências irreversíveis, atingindo os próprios produtores de risco. Para Beck, a ciência é a responsável pela definição de riscos ambientais "potenciais". Este processo estaria dividindo a sociedade em experts (identificadores de riscos) e não experts (perceptores de risco), produzindo uma politização da natureza. (Alonso; Costa, 2002). Essa 
abordagem foi amplamente difundida gerando programas de pesquisa em vários países, de forma que, segundo Giddens (1995), o conceito de risco ambiental teria sido exitoso por adentrar a própria teoria sociológica.

Paralelamente, no interior do campo da sociologia ambiental, a dimensão realista-materialista das abordagens começou a perder força, ganhando espaço abordagens afinadas com o construtivismo social. Assim, a sociologia ambiental passou a ter como seu principal objeto de estudo o aspecto eminentemente social dos problemas e questões ambientais, isto é, como o ambiente é percebido e construído socialmente como um problema ou questão pública. Dentre as formulações dessa corrente, uma das mais influentes é a síntese construcionista elaborada pelo canadense John A. Hannigan. Este enfoque, ao reivindicar o espaço das múltiplas realidades, invoca e defende o direito legítimo de que outras interpretações e saberes de outros agentes sociais também sejam levados em consideração. Assim, a percepção dos riscos provocou o questionamento da ciência e da tecnologia, trazendo o olhar construcionista. O construcionismo diz respeito ao modelo relacional-cognitivo que analisa o processo coletivo de construção de significados comuns que emprestam um sentido às relações dos indivíduos. A visão construcionista também se apresenta no estudo das formulações científicas que embasariam escolhas políticas. (Hannigan, 1997).

Hannigan (1997) considera que o principal caráter de uma análise construcionista é a preocupação com a forma pela qual as pessoas determinam o significado do seu mundo, e, portanto, no que diz respeito à questão ambiental, sua análise consiste em demonstrar que os problemas ambientais não existem por si mesmos, mas constituem o resultado de um processo de construção social multifacetado.

Contrariamente à grande parte da literatura sociológica existente, a formulação social não aceita sem críticas a existência de uma crise ambiental trazida de cima pelo crescimento desenfreado da população, sobreprodução, no- 
vas tecnologias perigosas, etc. Em vez disso, centra-se nos processos sociais, políticos e culturais através dos quais as condições ambientais são definidas como inaceitavelmente arriscadas e, portanto, litigáveis. [...] Os debates ambientais refletem a existência não só de uma ausência de certezas [...], mas antes a existência de certezas contraditórias: diversos conjuntos divergentes e mutuamente irreconciliáveis de convicções sobre os problemas ambientais com que nos defrontamos e as soluções que temos ao nosso dispor. (Hannigan, 1997, p. 45, destaque no original).

Dessa forma, em vez de caracterizar os problemas ambientais como entidades consolidadas, estes são representados como visões baseadas culturalmente e contestadas socialmente. Hannigan entende, portanto, que os problemas ambientais são semelhantes, em muitas formas, aos problemas sociais em geral. Contudo, destaca algumas diferenças importantes: os problemas ambientais, como o envenenamento por pesticidas e o aquecimento global, enquanto moralmente condenados, são ligados mais diretamente às descobertas e exigências científicas; e, além disso, embora sejam identificados com agentes humanos, têm uma base física mais impositiva do que os problemas sociais que estão mais enraizados nos problemas sociais que se converteram em questões públicas. (Hannigan, 1997, p. 54-5).

Hannigan (1997) considera ainda que a percepção destes problemas depende de um grande número de outros fatores, que se relacionam com a cultura e o conhecimento dos sujeitos sociais. Assim, para este autor a análise dos problemas ambientais trata do estudo dos dispositivos mediante os quais os processos de comunicação, processamento discursivo e orientação normativa formam e transformam o debate ambiental. Nessa perspectiva, as relações sociedade-natureza e os problemas ambientais a elas relacionados compreendem uma construção social que se exprime mediante uma variedade muito ampla de experiências negociadas, esten- 
dendo-se das formas de representação mítica até a científica. (Mattedi, 2003). Cabe destacar que Hannigan se refere a problemas ambientais tais como poluição e contaminação de alimentos, incluindo-os no conjunto de riscos característicos da sociedade moderna. (Hannigan, 1997, p. 239). Não faz referência, portanto, à expressão conflitos ambientais, sem tampouco destacar o aspecto conflitivo daquilo que denomina a construção dos problemas ambientais, sugerindo que essa construção passaria mais por negociações bem ou mal sucedidas. Contudo, essa abordagem exerceu/exerce forte influência na configuração do campo de estudos em conflitos ambientais no Brasil, como será discutido mais adiante.

À parte estes autores identificados especificamente com a sociologia ambiental, na composição do cenário da incorporação do ambiente pela sociologia, somam-se ainda, àqueles teóricos de sociologia geral, três outras subáreas da sociologia que se debruçaram sobre as temáticas ambientais: a) a sociologia rural - que em algumas abordagens passou a demarcar seu campo pouco a pouco da agricultura para o ambiente, como explicitamente demonstrado no livro Du rural à l'environnement (Mathieu; Jollivet, 1989); b) o estudo dos processos sociais de transformação da ideia de "natureza", como nos trabalhos de Kalaora (1993) sobre o lazer e a floresta e as pesquisas de Keith Thomas sobre a história das ideias ambientais (Thomas, 1988); e c) as definições de interdisciplinaridade, que ocupam uma grande parte dos estudos abordando as possibilidades de existência prática, institucional e epistemológica de uma socioantropologia do ambiente, como discutido nas publicações de Jollivet (1992) e Raynault (2004).

No entanto, também nestas abordagens entende-se que é sobretudo a construção social das relações sociedade-natureza que é destacada: seja na análise da construção de problemas pelos movimentos ambientalistas e ecologistas, da agenda social de instituições políticas, ou das novas formas de democracia, tudo leva a crer que o que interessa aos sociólogos 
é menos o ambiente do que as situações sociais que lhe perpassam, ou a construção que é proposta pelos movimentos sociais e políticos. (Boudes, 2008, p. 239).

Portanto, percebe-se que, se em sua origem a sociologia ambiental teve como objetivo romper com a primazia do social - entendido como exclusivamente humano - na análise sociológica, em seus desdobramentos esse objetivo não foi alcançado para além de um princípio geral. Assim como nas demais vertentes da sociologia que se propuseram a analisar temáticas ambientais, o foco manteve-se nas dinâmicas de construção e formulação - social - da questão ambiental.

Contudo, as propostas mais ousadas no sentido de se romper com a primazia do social nas análises vieram de outro campo de estudos, os Estudos Sociais da Ciência e da Tecnologia (ESCT). Estes, apesar de não partirem de problemáticas convencionalmente enquadradas como ambientais, ao analisarem o processo de produção do conhecimento científico e da elaboração e implantação de tecnologias se depararam, necessariamente, com a interface social-natural. No dizer de Jasanoff:

Configurando interações conflitivas e prolongadas entre pessoas, ideias, instituições e objetos materiais, o reconhecimento e a consideração de fenômenos como mudanças climáticas, armas biológicas, clonagem de mamíferos, alimentos geneticamente modificados, novas tecnologias reprodutivas, perda de biodiversidade, técnicas de miniaturização e crescimento da internet desafiam muitas das mais básicas categorias do pensamento social - como estrutura e agência, natureza e cultura, ciência e política, estado e sociedade. Os discursos dominantes da economia, da sociologia e da ciência política carecem de vocabulários que deem sentido aos processos desajeitados e irregulares através dos quais a produção da ciência e tecnologia se torna enredada por normas sociais e hierarquias. (Jasanoff, 2006, p. 2, tradução nossa). 
Na busca por termos conceituais que pudessem discutir as relações entre o ordenamento da natureza pelo conhecimento e pela tecnologia, e o ordenamento da 'sociedade' pelo poder e pela cultura (Jasanoff, 2006, p. 14, destaques no original), os ESCT trilharam diferentes caminhos (Bloor, 1982; Shappin; Schaffer, 1985; Collins, 1985; Haraway, 1991; Latour, 1994), mas que possuem como ponto comum a elaboração de uma linguagem para os híbridos, isto é, para explicar as realidades da experiência humana que emergem como aquisições conjuntas de empreendimentos científicos, técnicos e sociais. (Jasanoff, 2006, p. 17). E, nesse intuito, uma das formulações pioneiras e certamente uma das mais ousadas e desafiadoras no que diz respeito à coprodução sociedade-natureza é a abordagem de Bruno Latour e colaboradores da Teoria do Ator-Rede (ANT, na sigla em inglês). (Callon; Latour, 1981; Callon, 1986; Callon et al., 2001).

Latour, em seu ensaio monográfico Jamais fomos modernos (Latour, 1994), articula de maneira explícita temas dos ESCT com discussões da filosofia política, afirmando que a divisão sociedade-natureza é uma criação humana, ou, mais precisamente, ocidental. Seria um traço distintivo da modernidade a instauração de uma Constituição, que define e separa os humanos e não humanos, suas propriedades e suas relações. Contudo, esse projeto moderno de separação total entre humanos e não humanos, sociedade e natureza, não teria efetivamente sido perpetrado:

O buraco de ozônio é por demais social e por demais narrado para ser realmente natural; as estratégias das firmas e dos chefes de Estado, demasiado cheias de reações químicas para serem reduzidas ao poder e ao interesse; o discurso da ecosfera, por demais real e social para ser reduzido a efeitos de sentido. (Latour, 1994, p. 12).

Para estudar essas situações estranhas que a cultura intelectual não sabe bem classificar e atravessar o corte que separa os conhecimentos exatos dos exercícios de poder, digamos, a natureza da cultura (Latour, 1994, 
p. 9), Latour parte da noção de redes sociotécnicas, com o objetivo de tornar visíveis as conexões que fazem com que tanto objetos "naturais", como o buraco da camada de ozônio, quanto objetos "sociais", como peritos ou governos, possam ser vistos associados como atores-rede, membros heterogêneos que atravessam a separação constitucional entre sociedade e natureza.

Nesse sentido, seu programa de pesquisa reconhece agência a humanos e também a não humanos, que, de meros objetos a serem desconsiderados da teoria sociológica, ou desconstruídos em sua materialidade como fruto da construção social, se tornam mediadores:

Na perspectiva moderna, a natureza e a sociedade permitem a explicação porque elas, em si, não precisam ser explicadas. Existem, é claro, os intermediários cujo papel é justamente o de criar uma ligação entre as duas, mas estes só podem criar as ligações porque, justamente, não possuem qualquer dignidade ontológica. Nada fazem além de transportar, veicular, deslocar a potência dos dois únicos seres reais, natureza e sociedade. [...] No entanto, as metamorfoses [da natureza e da sociedade] tornam-se explicáveis se redistribuirmos a essência por todos os seres que compõem essa história. Mas então eles deixam de ser simples intermediários mais ou menos fiéis. Tornam-se mediadores, ou seja, atores dotados da capacidade de traduzir aquilo que eles transportam, de redefini-lo, desdobrá-lo, e também de traí-lo. (Latour, 1994, p. 79).

Mediante vários anos de estudos sobre ciência, tecnologia e a interdependência do natural, do social e do material, Latour postula como conclusões que: a "natureza" é o resultado, e não a causa, da resolução de controvérsias científicas; o laboratório é um microcosmo de grandes agregações de poder; objetos materiais e artefatos, como fechaduras, incorporam e efetuam normas sociais; grandes instituições sociais, como o capitalismo ou o mercado, são construídas pelos mesmos meios usados 
pelos cientistas para fazerem representações persuasivas da natureza; e a essência da modernidade está em sua dedicação em "purificar" as redes híbridas de natureza e cultura.

Latour (2007) constrói ainda uma crítica direta à abordagem de Beck (1995) acerca da globalização, distanciando-se da retórica da urgência e dos imperativos ambientais. Para tanto, Latour recusa o que denomina "mononaturalismo de Beck", inerente a um mundo com uma natureza una $^{7}$, mas estruturado pelo mundo ocidental, acessível apenas pela ciência moderna. Em oposição, ressalta a necessidade de se conceber um "pluriverso", composto de uma possível pluralidade de naturezas.

Esse posicionamento está vinculado à proposição cosmopolítica da filósofa belga Isabelle Stengers. Em seu ensaio composto por sete volumes intitulado Cosmopolitiques (Stengers, 2003), a autora analisa a produção do conhecimento científico à luz da prática filosófica dessa produção. Para nomear as disputas metafísicas implicadas no fechamento de controvérsias científicas e no ordenamento da vida social no qual essas controvérsias se inserem, Stengers (2003) escolhe o termo cosmopolítica, mas conferindo a este um sentido que se distancia da tradição kantiana:

Tudo aquilo que nós hoje julgamos normal, sinônimo de progresso, foi inventado através de movimentos de luta, inventando para o cidadão coletivo identidades novas, transformando os modos de pertencimento, as exigências, os direitos, e as obrigações que então decorrem. Mas essa dinâmica de invenção não tem nada de neutra. Ela define nossa "ecologia" sob um modo político, que nos traz a obrigação de aceitar a prova que constitui a distinção entre condição e restrição. [...] É portanto por contraste a Kant, e não em sua filiação, que eu retomarei o termo "cosmopolítica" [...]. O neutrino não deve felizmente sua

\footnotetext{
${ }^{7}$ Essa crítica se estende também a abordagens clássicas da antropologia. (Latour; Schwartz; Charvolin, 1998).
} 
existência ao direito, e sua passagem à existência rompeu, e impôs a se reformular, muitas das regras até então concernentes à definição do modo de existência legítimo de uma partícula física. Afirmar que o neutrino tem o modo de existência de um "faitiche", produto e produtor de uma prática, existente por ela e a fazendo existir, constitui então um primeiro passo que engaja uma saída do horizonte kantiano onde a paz deveria ser "nossa" paz, onde o comércio deveria se limitar aos bens e às ideias, em detrimento dos mundos múltiplos que fazem existir nossos faitiches e nossos fetiches. (Stengers, 2003a, p.85; Stengers, 2003b, p. 332, destaques no original, tradução nossa).

Partindo dessa proposição, Latour (2007) elabora a ideia de cosmopolítica como as políticas da crise da modernidade. Considera que elas têm por objetivo a composição de um mundo comum, de um cosmos, mas que deve ser realizada com os outros, os excluídos da modernidade política republicana: os não modernos - as comunidades do Sul, comunidades rurais - e os não humanos - os artefatos científicos, entidades ambientais - e/ ou sobrenaturais - as religiões, crenças, fetiches. Porque, segundo Latour,

Não existem mais externalidades, não existe mais ambiente, não existe mais a natureza-depósito, ou periferia distante e exótica, onde estocar e esconder as consequências de nossos atos, como exprime Ülrich Beck. As externalidades retornaram, estão aí, e resistem. (Latour, 2007, p. 47, tradução nossa).

Dessa forma, o autor rompe com preceitos consolidados das teorias sociológicas, bem como com as definições de campo da abordagem crítica bourdiniana: sociologia, antropologia, filosofia se mesclam, em uma "ciência das ações" ou mesmo uma "associologia" (Latour, 2005, p. 45-8), gerando um arcabouço tão fértil quanto controverso.

No entanto, inúmeras são as críticas realizadas a esta abordagem e seus desdobramentos, sendo provavelmente as mais persuasivas as que dizem respeito à dimensão do poder. Como sintetiza Jasanoff: 
[...] quando a teoria do ator-rede se confronta com a natureza do poder, como frequentemente acontece, ela se desvia das questões sobre pessoas, instituições, ideias e preferências que são da maior importância política. Quem perde e quem ganha através da constituição da rede? Quais são os benefícios e os ônus (re)distribuídos pelas ou através das redes? (Jasanoff, 2006, p. 23, tradução nossa).

Essas são perguntas não bem respondidas por Latour, que visa demarcar a relevância de sua abordagem justamente no distanciamento da crítica como tradição sociológica, na qual o poder exerce papel de categoria central de análise. Opostamente, Latour (1994, p. 10) declara: não estamos falando do contexto social e dos interesses do poder, mas sim do envolvimento de coletivos e objetos. Contudo, a despeito das críticas não respondidas e de suas lacunas, as proposições ricas e provocativas de Latour e da Teoria do Ator-Rede efetivamente conseguiram abrir espaço para uma série de novas abordagens que não partem do pressuposto da separação sociedade-natureza em suas análises.

Neste cenário, especificamente no que tange ao debate ambiental, além dos artigos e livros do próprio Latour sobre o tema (Latour et al., 1998; Latour, 2003), são as abordagens pragmáticas sobre controvérsias científicas aquelas que mais se aproximam da análise de conflitos. Destacam-se nesse sentido as pesquisas conduzidas no Groupe de Sociologie Pragmatique et Reflexive (GSPR), lideradas por Francis Chateauraynaud, sobre as controvérsias erigidas em torno dos alarmes ambientais. Examinando dossiês sobre príons, amianto e energia nuclear (Chateauraynaud; Torny, 1999) e sobre pesticidas e organismos geneticamente modificados (Lamine; Tétart; Chateauraynaud, 2010), os autores constituem séries longitudinais nas quais analisam diferentes configurações das arenas públicas. Consideram que é no bojo das controvérsias científicas que se dão as disputas e as novas interconexões entre esferas de atividades distintas, 
com suas diferentes implicações. (Chateauraynaud; Torny, 2005). Nessa abordagem, o ambiente é parte integrante - ou, no vocabulário dos autores, é agenciado - em redes sociotécnicas que emergem e se estabilizam por meio de processos de definição e de resolução de situações problemáticas, como por exemplo os riscos de terremoto ou de inundação.

Cabe ainda mencionar que a linha de pesquisa que, diferentemente do encontrado na maior parte da literatura internacional, faz referência específica ao termo conflitos ambientais, toma por centralidade os mecanismos de resolução de tais conflitos. Tal qual sumarizado por Libiszewski (1993), a corrente de resolução de conflitos ambientais emerge como um desdobramento do campo de resolução de conflitos sociais e segurança, formulado para mitigar causas de violência. Enquanto no Brasil pouco se tem publicado a respeito dessa abordagem e o uso de métodos de resolução de conflitos é bastante incipiente (Viegas, 2009), ainda que em expansão (Acselrad; Bezerra, 2010), em países como Estados Unidos, Canadá, Noruega e Finlândia há muitos registros na literatura sobre o uso de tais instrumentos e discussões sobre as estratégias, categorizadas como procedimentos de negociação direta, conciliação, facilitação, mediação e a arbitragem. (Viegas, 2009). Algumas referências nesse sentido são os trabalhos de Bingham (1986) e Amy (1987), que analisam experiências de mediação nos Estados Unidos; o de Ozawa (1996), que discute o papel da ciência como ferramenta facilitadora da resolução, também nos Estados Unidos; e o de Rannikko (1996), que analisa a tomada de consciência ambiental na resolução de conflitos na Finlândia. Contudo, tais abordagens concentram-se em estratégias metodológicas e técnicas de resolução, carecendo de problematizações acerca das características dos conflitos e das partes envolvidas, e da real capacidade de resolução atingida.

Pode-se perceber, portanto, que a incorporação do ambiente pela sociologia nas pesquisas provenientes da Europa, dos Estados Unidos e do 
Canadá tem como traço comum o caráter científico e técnico no qual são formuladas as questões, seja para interpretá-lo como algo modulado por incertezas decorrentes da sociedade de risco, seja por controvérsias científicas, ou ainda passível de demandas por instrumentos de resolução. O ambiente é, nessas abordagens, uma questão moderna: um problema das sociedades industriais avançadas, um risco a que se está exposto, uma construção social, ou redes sociotécnicas. Um esquema simplificado desse ordenamento temático das linhas de pesquisa pode ser visualizado na figura 01 abaixo:
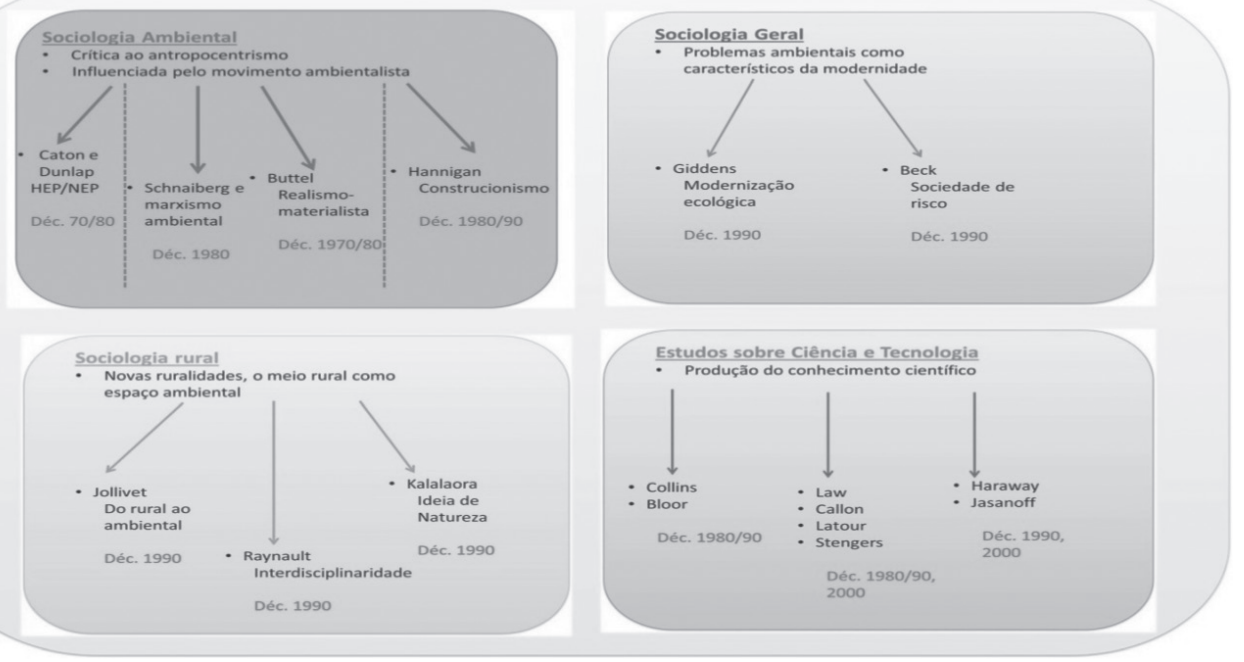

Figura 1. Esquema das abordagens e autores no tema da sociologia e ambiente na Europa, Estados Unidos e Canadá. 


\section{Ambiente e sociologia na América Latina e no Brasil: a perspectiva dos conflitos ambientais}

No cenário latino-americano a relação entre ambiente e sociologia ganha contornos diferentes. Nas pesquisas ${ }^{8}$ as disputas em torno da biodiversidade parecem ser o mote central. Esta é explicitada por Escobar e Pardo (2005) da seguinte forma:

O conceito de biodiversidade tem transformado os parâmetros de avaliação da natureza e as disputas pelo acesso aos recursos naturais. [...] O crescente discurso sobre a biodiversidade é o resultado da problematização do biológico, pois COloca as áreas de floresta tropical úmida numa posição biopolítica global fundamental. (Escobar; Pardo, 2005, p. 345-6).

Este discurso da biodiversidade promete, segundo Escobar (1999), salvar a natureza das práticas que causam sua degradação, e em seu lugar instituir uma "cultura de conservação". Esse autor afirma que esta é uma nova maneira de se falar da natureza, inserida em uma profunda mediação tecnocientífica. Ainda, Escobar e Pardo (2005, p. 347) ressaltam que nesse discurso de produção de biodiversidade estão envolvidos diferentes atores, "desde as ONGs do Norte, jardins botânicos, universidades e corporações até os recentemente criados institutos para a biodiversidade no Terceiro Mundo, comunidades e ativistas locais", cada um com o seu quadro interpretativo sobre o que é e o que deveria ser a biodiversidade. Os autores citados se detêm sobre a análise do Pacífico colombiano, que tem passado por intensas transformações, mas destacam que processos semelhantes estão em curso na Costa Rica, no Brasil e no Equador, entre outros.

\footnotetext{
${ }^{8}$ Considera-se aqui o país de origem dos autores, e não necessariamente o país em que se situam as instituições às quais estão vinculados, visto que muitos dos autores deste grupo se encontram vinculados a universidades nos Estados Unidos ou na Europa.
} 
A partir daí, Escobar (2005) considera a questão ambiental uma contraposição à concepção globalocêntrica da sociedade. Por isso, propõe a defesa do conhecimento local como estratégia política e epistemológica, e considera que

Se o objetivo [...] é tornar visíveis as práticas das diferenças culturais e ecológicas que poderiam servir de base para alternativas, faz-se necessário reconhecer que esses objetivos estão indissoluvelmente vinculados a concepções de localidade, de lugar, e de uma consciência baseada no lugar. O lugar - como a cultura local - pode ser considerado "o outro" da globalização, de maneira que uma discussão do lugar deveria apresentar uma perspectiva importante para repensar a globalização e a questão das alternativas ao capitalismo e à modernidade. (Escobar, 2005, p.150).

Nessa perspectiva, Escobar aponta que a luta pelo território levada a cabo por grupos étnicos é uma luta cultural por autonomia e pela autodeterminação, na qual a mobilização desses grupos para exercer o controle sobre os usos da biodiversidade contida nos seus territórios constitui um fator imprescindível para a sua sobrevivência cultural e política. Portanto, esses processos são, afirmam Escobar e Pardo (2005), eminentemente conflitivos: tomam forma conflitos sobre como conhecer ou como é conhecida a biodiversidade, e conflitos entre práticas culturais e significados contrastantes. Estaria em curso, nesses casos, uma política cultural da natureza, onde

(...) atores sociais, moldados ou caracterizados por diferentes significados e práticas culturais, entram em conflito. A noção de política cultural pressupõe que os significados e práticas culturais - nomeadamente aquelas que são teorizadas como marginais, de oposição, minoritárias, residuais, emergentes, alternativas, dissidentes e similares, concebidas por relação a uma ordem cultural dominante - são fonte de processos que podem ser considerados políticos. Essa política cultural altera as práticas e a compreensão familiar que se tem da natureza, ao mesmo tempo em que procura 
libertar, tanto mentalmente quanto na própria natureza, as ecologias locais dos sistemas enraizados em fatores de classe e gênero e do domínio étnico e cultural. (Escobar; Pardo, 2005, p. 345).

Outro aspecto importante na análise de Escobar (1998, p. 204, tradução nossa) é o destaque para o fato de que as florestas tropicais são percebidas como as formas mais naturais da natureza ainda existente na Terra, habitadas pelas pessoas mais naturais (povos aborígenes) que possuem os conhecimentos também mais naturais para salvar a natureza. Assim, o discurso da biodiversidade, ao implicar na ressignificação das florestas tropicais (como valiosa reserva genética), ressignifica também seus habitantes (como guardiães da natureza) e seus conhecimentos (como conhecimentos tradicionais de se conservar a natureza). O autor afirma que se este grupo de ressignificações implicará em novas formas de colonização da paisagem biofísica e humana ou se vai contribuir na criação de novas possibilidades políticas para as comunidades locais, é uma questão em aberto. A resposta depende, segundo Escobar (1999, p. 218, tradução nossa), do grau com que as comunidades locais irão se apropriar e utilizar os novos significados para atingir seus próprios objetivos, relacionando-os com outras identidades, circuitos de conhecimentos e projetos políticos.

É também a problematização da configuração de um nativo ecológico que orienta os trabalhos de Astrid Ulloa sobre ambiente e conflitos. (Ulloa, 2004). A autora afirma que as imagens de um nativo ecológico se converteram em práticas políticas importantes, tanto para os movimentos indígenas quanto para os ambientalistas, estratégia que também permitiu a coalisão destes dois movimentos. Nessa estratégia, os ambientalistas evocam o nativo ecológico como um ator essencial em seus discursos, enquanto os povos indígenas defendem que sua contribuição cultural aos discursos ambientais é o respeito que têm pela natureza. Contudo, Ulloa (2004) considera que essa identificação dos povos indígenas à ecologia 
está relacionada aos estereótipos que há séculos modulam as representações sociais sobre os indígenas, as quais se vinculam às noções ocidentais de natureza e cultura, situando os indígenas "em relações desiguais de poder, que se assemelham aos processos coloniais". (Ulloa, 2004, p. 259).

Com base nessa discussão, Ulloa (2011, p. 31) parte da noção de governamentalidade para analisar a relação entre indígenas e ambiente, até transformá-la em ecogovernamentalidade e estabelecer como esta se estrutura com o surgimento de uma nova formação discursiva (o ambientalismo), o multiculturalismo, os direitos indígenas e ambientais, e uma governabilidade global. Na ecogovernamentalidade tal qual proposta pela autora, as organizações ambientais (governamentais e não governamentais), os atores sociais (inclusive os povos indígenas e suas políticas culturais e ambientais), os ambientalistas e as comunidades científicas, entre outros, são agentes no processo para regular e dirigir as ações sociais de acordo com lógicas e discursos que contribuem para o desenvolvimento de uma concepção emergente de governamentalidade ambiental global. No entanto, isto implica em negociações e conflitos, assim como [em] acordos. (Ulloa, 2011, p. 32).

Por sua vez, assim como Escobar e Pardo (2005) analisam os conflitos em termos de uma política cultural na qual a diferença é apresentada como formadora de identidades e como bandeira na proposição política, é também o viés de uma política diferenciada o proposto por Marisol de la Cadena na interpretação dos conflitos de povos nativos com empresas mineradoras no Peru (De la Cadena, 2010). Contudo, neste caso se trata de uma diferença em outros termos. Ao analisar as reconfigurações que vêm ocorrendo na América Latina nos últimos anos, em particular a partir do estudo das mobilizações contra a exploração mineral na montanha Ausangate, em Cuzco, De la Cadena discute a presença política de atores que 
[...] sendo outros que humanos, as disciplinas dominantes definem como pertencendo ou à esfera da natureza (onde eles deveriam ser conhecidos pela ciência) ou aos campos metafísicos e simbólicos do conhecimento. (De la Cadena, 2010, p. 336, tradução nossa).

Dessa forma, a autora se alinha aos ESCT, mas com particular influência da proposição cosmopolítica de Stengers (2003a), abrindo pistas para uma profícua análise da prática política e de conflitos que não partem dos pressupostos da separação sociedade e natureza. Muito pelo contrário, coloca essa separação como parte essencial da análise:

O campo político que atualmente reconhecemos como tal não foi moldado apenas distinguindo-se amigos de inimigos entre os humanos, mas também pela separação antitética entre "Humanidade" e "Natureza". Juntas, estas duas antíteses - entre humanidade e natureza e entre humanos supostamente superiores e inferiores - declararam a extinção gradual dos seres outros que humanos e dos mundos nos quais eles existem. O pluriverso, os múltiplos mundos que Schmitt considerava cruciais para a possibilidade da política, desapareceu. Em troca, um único mundo fez sua aparição, habitado por vários povos (a quem agora chamamos culturas), mais ou menos distanciados de uma única "Natureza" (Descola, 1996; Haraway, 1991; Latour, 1993; Viveiros de Castro, 2004). (De la Cadena, 2010, p. 345, tradução nossa).

De la Cadena (2010, p. 362) faz assim a defesa de uma política pluriversa - ou, de uma cosmopolítica - na qual diferentes mundos com suas formações socionaturais e suas visões conflitantes possam ser considerados. Dessa forma, liberadas de sua representação exclusiva como 'Natureza', as múltiplas e heterogêneas ontologias da montanha (incluindo-se sua possibilidade como repositório de riqueza mineral) pesariam em projetos políticos heterogêneos, adicionando dimensões aos conflitos. 
Percebe-se, portanto, que, seja associada ao discurso da biodiversidade, seja como componente inerente à cosmopolítica, a correlação entre ambiente e conflitos adquire posição central nessas abordagens.

$\mathrm{Na}$ literatura brasileira, por sua vez, foram os debates sobre sustentabilidade, e pouco a pouco a análise de conflitos, que parecem ter orientado a discussão ambiental na sociologia. De acordo com Ferreira (2005, p. 110), uma das questões centrais que têm orientado essa área de pesquisas, e que tem sido constantemente reformulada e recolocada, é

como e por que se dá a formação de grupos sociais para atuarem em relação à questão ambiental, e qual sua influência sobre a mudança social em direção à conservação e à sustentabilidade no uso dos recursos naturais?

(Ferreira, 2005, p. 110).

A autora, ao analisar o acúmulo até então realizado na temática ambiental, constata que

a) há definitivamente no Brasil uma arena especificamente ambiental, orientada pelo processo decisório que estabelece normas e regras de utilização de recursos; b) a conservação e a sustentabilidade são parte de um projeto socialmente construído através da tensão entre interesses, interpretações e escolhas tornadas públicas nas diversas arenas estabelecidas nos níveis local, nacional e internacional; c) há hoje uma interação, conflituosa ou não, mas certamente intensa, entre grupos sociais diversos e diversificados, o que tem aspectos muito positivos e outros preocupantes. (Ferreira, 2005, p.114).

A arena ambiental brasileira a que se refere a autora já foi discutida em distintas revisões sobre as linhas de pesquisa em ambiente e ciências sociais no Brasil (Vieira, 1992; Alonso; Costa, 2002; Ferreira, 2005, entre outros), cabendo aqui ressaltar o espaço dos conflitos ambientais enquanto campo de investigação nesse contexto. Grosso modo, a partir dessas revisões contata-se que podem ser identificados três grandes grupos de 
autores e abordagens que configuram os conflitos ambientais como campo de investigação no Brasil atualmente: a) aqueles que dialogam com a sociologia ambiental internacional, considerada de modo amplo, orientando suas pesquisas a partir dos debates sobre arenas públicas, sociedade de risco, modernização ecológica, sustentabilidade e sociologia rural e interdisciplinaridade (Fuks, 2001; Ferreira, 1996; Almeida, 1997; Guivant, 1998; Brandenburg, 2005, entre outros); b) autores que se apropriam do arcabouço teórico-metodológico da sociologia crítica, influenciados pelas pesquisas de Pierre Bourdieu, e discutem conflitos ambientais a partir de relações simbólicas e de poder/dominação (Lopes, 2004; Acselrad, 2004; Zhouri; Laschefski, 2010, entre outros); e c) autores identificados com a antropologia, que discutem conflitos ambientais a partir de análises sobre povos tradicionais e grandes projetos de desenvolvimento. (Ribeiro, 1991; Almeida, 1996; Magalhães, 2007; Carneiro da Cunha, 2009).

Assim, ainda que se possa considerar que este seja um campo em formação (Alonso; Costa, 2000; Zhouri; Laschefski, 2010), a relevância do tema conflitos ambientais no cenário nacional pode ser atestada pela presença de grupos de trabalho voltados para a sua discussão nos principais encontros brasileiros de ciências sociais, como nos encontros anuais da Associação Nacional de Pesquisa e Pós-Graduação em Ciências Sociais (ANPOCS), nos congressos da Sociedade Brasileira de Sociologia (SBS), nos encontros bianuais da Associação Nacional de Pesquisa e Pós-Graduação em Ambiente e Sociedade (ANPPAS), nas reuniões da Associação Brasileira de Antropologia (ABA), entre outros. Alguns balanços sobre a produção em conflitos ambientais vêm sendo publicados (Acselrad, 2004; Carneiro, 2009; Zhouri; Laschefski, 2010), e dentre as pesquisas mais emblemáticas desse campo cabe destacar em particular algumas abordagens.

A proposta de Hannigan (1997) de deslocar o foco de investigação da "condição objetiva" dos assuntos públicos estudados para a dinâmi- 
ca sociopolítica que envolve a mobilização da atenção e a compreensão pública desses assuntos é incorporada de forma seminal na definição dos conflitos ambientais tais como analisados por Fuks (1996; 2000; 2001). Esse autor, para entender os conflitos ambientais em espaços urbanos no Rio de Janeiro, articula a perspectiva construcionista de Hanningan ao modelo de sistema de arenas públicas, de Hilgartner e Bosk (1988), formulando uma análise centrada na dinâmica argumentativa dos conflitos sociais, entendida como espaço de elaboração e veiculação de versões alternativas a respeito de assuntos públicos. (Fuks, 2000, p. 02). Para tal, considera contribuições das pesquisas sobre definição de agendas, sociologia dos problemas sociais, movimentos sociais e psicologia social, e propõe que a vida política constitui-se como arena argumentativa, na qual os partidos políticos, a mídia, os grupos organizados e o poder público participam de um permanente processo de debate. Para o autor, esse processo emerge da disputa, situada em arenas específicas, entre uma (virtual) pluralidade de versões, embora as condições diferenciadas de participação impliquem vantagens para certos atores e, no limite, o silêncio de outros. Considera, ainda, que a definição dos problemas ambientais seria uma clara demonstração deste processo.

Como elemento-chave para compreender a dinâmica argumentativa proposta por Fuks, ressalta-se que essa abordagem estabelece como foco de investigação os processos sociais responsáveis pela emergência de um novo assunto público e as disputas em torno de sua definição. Ainda, considera que a emergência de questões na agenda pública pode ser explicada mais em termos da dinâmica social e política do que pelos atributos intrínsecos dos assuntos em disputa, ou seja, da gravidade "objetiva" dos problemas em questão. Assim, o sucesso dessa emergência estaria relacionado com os recursos materiais, organizacionais e simbólicos disponíveis para determinado grupo. 
O conceito de sistema de arenas públicas sugere a saliência dos assuntos que nele circulam. Supõe-se, antes de tudo, a visibilidade das ações e dos debates a eles associados. No que diz respeito à questão ambiental, o ambiente pode ser entendido nessa abordagem como o assunto a se consolidar nas arenas de controvérsia pública. Isso ocorre porque, nesta perspectiva, o ambiente como lugar de conflito é recodificado por meio do sentido que ele passa a representar para diferentes atores. Fuks afirma que

o meio ambiente como um bem universal e uniforme não existe no campo das relações sociais. Nem tampouco existe um sujeito universal preocupado com a proteção ambiental. Existem, sim, situações concretas, passíveis de se transformarem em mobilização de grupos sociais específicos, que contam com acervos definidos de recursos (simbólicos e organizacionais) e que falam a partir de percepções, valores, projetos, necessidades e interesses pertinentes ao lugar que ocupam. Isso significa que esses grupos atribuem valores próprios, apresentam demandas específicas e elaboram as suas compreensões a respeito do meio ambiente. (Fuks, 2001, p. 97).

Além de se situarem em um campo de disputa em torno de casos particulares, nessa abordagem os conflitos constituem também um espaço relevante no processo de elaboração e circulação públicas de versões a respeito do assunto em questão. Nesse contexto, os conflitos ambientais são as arenas específicas em que emergem argumentos aptos a participar da disputa pela definição do ambiente como problema social. Isso significa que as versões elaboradas no contexto das disputas localizadas são, ao mesmo tempo, permeadas e contribuem para a constituição do quadro de referência mais amplo a partir do qual um determinado problema social é elaborado e tratado. Essas versões são alimentadas pelo que Fuks (2001) denomina "pacotes interpretativos", que, neste enfoque, fornecem repertórios de recursos retóricos para elaboração de relatos a respeito de eventos significativos. 
Em sua análise, Fuks (2001) ressalta em diversos momentos a capacidade do conflito ambiental de atualizar antigas disputas. Afirma que, no Rio de Janeiro, o incentivo propiciado pelos novos recursos judiciais e administrativos para que setores organizados da sociedade civil formulem suas demandas a órgãos públicos em termos ambientais estimula a recodificação dos problemas e dos conflitos urbanos. Por isso, para o autor,

O conflito ambiental torna-se, então, o campo de batalha para o qual vem se deslocando a luta relativa à ocupação e uso do solo. Isso desempenha um papel fundamental na caracterização "local" do meio ambiente como problema social, que assume a forma de redefinição de outros conflitos e problemas urbanos. (Fuks, 2001, p. 96).

Essa conclusão é bastante similar à proposta por Lopes (2004; 2006), ainda que este parta de uma matriz teórica diferente. Ao acompanhar o processo conflitivo em torno da Companhia Siderúrgica Nacional em Volta Redonda, Lopes (2004) constata que as disputas se deslocam das lutas trabalhistas iniciadas na década de 1980 à preocupação ambiental como questão pública, chegando a polarizar as novas lutas na cidade nos anos [19]90. Esse fenômeno Lopes (2004) interpreta como ambientalização dos conflitos sociais. O termo ambientalização é explicado pelo autor como um neologismo semelhante a alguns outros usados nas ciências sociais para designar novos fenômenos ou novas percepções de fenômenos vistos da perspectiva de um processo:

Assim, os termos "industrialização" ou "proletarização" (este último, usado por Marx) foram indicativos de novos fenômenos no século XIX, como se poderia também falar de tendências de "desindustrialização" e de "subproletarização" desde o final do século XX. Ou ainda, num sentido mais estrito, os termos usados por Norbert Elias [...] para caracterizar processos históricos passados percebidos de forma nova como importantes, tais como "curialização" - designativo da formação das sociedades de corte europeias entre 
os séculos XIV e XVIII - ou "esportificação" - que ganharam o mundo no século XX a partir da Inglaterra do século XIX. (Lopes, 2006, p. 34).

O sufixo comum a todos esses termos indicaria um processo histórico de construção de fenômenos, associado a um processo de interiorização pelas pessoas e pelos grupos sociais; e, segundo o autor, no caso da ambientalização, ocorreria uma interiorização das diferentes facetas da questão pública do "meio ambiente". Essa incorporação e essa naturalização de uma nova questão pública poderiam ser notadas pela transformação na forma e na linguagem de conflitos sociais e na sua institucionalização parcial (Lopes, 2006, p. 35). No entanto, a dinâmica própria dos conflitos sociais não seria em seu cerne alterada pela incorporação do discurso ambiental: a questão ambiental seria uma nova fonte de legitimidade e de argumentação nos conflitos, mas cujo sucesso enquanto processo dependeria de reações, contra-ataques, restaurações que, de forma similar aos conflitos sociais em geral,

[...] variam entre a ilegalidade e ilegitimidade não fiscalizada de uma continuidade de práticas de acumulação primitiva ambiental até a violência doce do uso da linguagem e procedimentos ambientalmente corretos no contexto da dominação empresarial exercida de forma socialmente irresponsável. (Lopes, 2006, p. 32).

Isto é, ao interpretar os conflitos ambientais como processos de incorporação da linguagem e das práticas ambientais pelos grupos sociais em disputa, o autor situa a originalidade dos conflitos na forma e na linguagem empregadas, na inculcação do novo domínio do ambiente [...] se tornando um habitus, no sentido analisado por Bourdieu (Lopes, 2004, p. 235), e não em prerrogativas do conflito.

Assim como na abordagem de Fuks (2001), o que torna então certa versão relevante no processo de definição de um problema social é a sua 
virtual universalidade, ou seja, a sua condição de candidata à adoção, por qualquer ator, nas arenas da ação e do debate público. Este aspecto também é ressaltado por Acselrad (2004, p. 19) em sua problematização dos conflitos ambientais, ao afirmar que, nestes contextos, se observa "uma busca pela universalização de causas parcelares através de valores compartilháveis que tornam os atos justificáveis". Entende-se então que é na esfera simbólica que se desenvolve a disputa de legitimidade dos discursos que buscam afirmar suas respectivas capacidades potenciais de operar tal universalização.

Acselrad (2004), admitindo também uma postura construcionista, afirma que

[...] o meio ambiente é uma construção variável no tempo e no espaço, um recurso argumentativo a que atores sociais recorrem discursivamente através de estratégias de localização conceitual nas condições específicas da luta social por "mudança ambiental", ou seja, pela afirmação de certos projetos em contextos de desigualdade sociopolítica. (Acselrad, 2004, p. 19, destaque nosso).

Para esse autor, portanto, na perspectiva das ciências sociais se trata de pensar o ambiente como um mundo material socializado e dotado de significados, sendo os objetos que constituem o 'ambiente' [...] culturais e históricos. (Acselrad, 2004, p. 7). Para Acselrad (2005), os conflitos ambientais ocorrem quando há um desacordo no interior do arranjo espacial de atividades de uma localidade ou região, implicando na ameaça da continuidade de um tipo de ocupação do território pela maneira como outras atividades, espacialmente conexas, são conduzidas. Ou seja, a emergência do conflito tem como fator explicativo o processo pelo qual,

com a dinâmica da acumulação, por intensidade ou extensão, um certo número de "acordos simbióticos" entre as distintas práticas espaciais é rompido, ou verifica-se uma recusa socialmente organizada frente a um novo tipo de acordo proposto 
pelos agentes econômicos, seja a construção de barragens, a exploração de minérios ou a implantação de uma infraestrutura perigosa, por exemplo. (Acselrad, 2005, p. 8).

Essa análise sobre os conflitos ambientais a partir de uma perspectiva inspirada pela sociologia crítica influenciou em grande parte os trabalhos decorrentes no Brasil, tendo como um de seus principais eixos a valorização das disputas por apropriação social da natureza nestes conflitos, destacando a sua dupla dimensão, material e simbólica. Segundo este autor, as lutas por "recursos ambientais" são simultaneamente lutas por sentidos culturais, e os conflitos ambientais devem ser analisados, portanto, simultaneamente nos espaços de apropriação material e simbólica dos recursos do território. Ambos são considerados espaços onde se desenrolam disputas sociais em geral, onde o modo de distribuição de poder pode ser objeto de contestação.

Ainda de acordo com Acselrad (2004), no primeiro espaço se desenvolvem as lutas sociais, econômicas e políticas pela apropriação dos diferentes tipos de capital, pela mudança ou conservação da estrutura de distribuição de poder. No segundo, que seria o espaço das representações, desenvolve-se uma luta simbólica para impor as categorias que legitimam ou deslegitimam a distribuição de poder sobre os distintos tipos de capital.

$\mathrm{O}$ autor prossegue afirmando que a importância desse tipo de conflitos decorre do fato de eles exprimirem as contradições internas aos modelos de desenvolvimento. (Acselrad, 2004; 2005). Salienta que em cada configuração de modelo de desenvolvimento tende-se a encontrar modalidades específicas de conflitos ambientais dominantes, mas que, regra geral, a concentração de posse sobre o elemento da base material da sociedade por meio de grandes projetos de apropriação do espaço e do ambiente tem efeitos de desestruturação de ecossistemas, ao mesmo tempo em que concentra pequenos produtores, populações ribeirinhas e deslocados compulsórios em terras exíguas. Assim, os conflitos ambientais eclodem, nessa perspectiva, quando 
os despossuídos passam a reclamar [...] maior acesso aos recursos como água, terra fértil, etc., denunciando o comprometimento de suas atividades pela queda da produtividade dos sistemas biofísicos de que dependiam e risco de perda de durabilidade da base material necessária à sua reprodução sociocultural. (Acselrad, 2004, p. 27).

Andréa Zhouri e seus colaboradores partem dessa conceituação dos conflitos ambientais para orientar a sua abordagem. (Zhouri, 2004; Zhouri; Laschefski, Pereira, 2005; Zhouri; Laschefski, 2010). Baseado na experiência de pesquisa sobre os processos envolvendo o licenciamento ambiental de usinas hidrelétricas em Minas Gerais, o Grupo de Estudos em Temáticas Ambientais da Universidade Federal de Minas Gerais - GESTA/ UFMG analisa distintas experiências de conflito ambiental, enfatizando-se o confronto entre racionalidades, via de regra no "campo de lutas" entre de um lado, as populações ribeirinhas que resguardam a terra como patrimônio da família e da comunidade, defendido pela memória coletiva e por regras de uso e compartilhamento dos recursos; de outro lado, o Setor Elétrico, incluindo-se o Estado e empreendedores públicos e privados que, a partir de uma ótica de mercado, entendem o território como propriedade, e, como tal, uma mercadoria passível de valoração monetária. (Zhouri; Oliveira, 2007, p. 120).

Ao publicar uma compilação de pesquisas sobre os conflitos ambientais cujo título é Desenvolvimento e conflitos ambientais, Zhouri e Laschefski (2010) destacam que estes conflitos são caracterizados pela diversidade e pela heterogeneidade dos atores e dos seus modos de pensar o mundo e nele projetar o futuro. Em seu esforço para, a partir dos processos empíricos, identificar especificidades e características de tais conflitos, os autores elaboram uma tipologia, organizando-os em conflitos ambientais distributivos, conflitos ambientais espaciais e conflitos ambientais territoriais. Contudo, ressaltam que tal categorização atende a fins heurísticos, e que em geral se observa uma dinâmica dialética entre os 
tipos, sendo corrente sua coexistência ou mesmo transformação de suas consequências em conflitos que pertencem a outro tipo.

Para Zhouri e colaboradores, os conflitos ambientais são decorrentes da implantação de um "paradigma da adequação ambiental", oposto ao projeto de sustentabilidade:

Isso ocorre porque projetos industriais, concebidos no âmbito de uma política de desenvolvimento voltada para o crescimento econômico com ênfase na exportação, são concentradores de "espaço ambiental" (Opschoor, 1995), gerando, assim, conflitos sociais. Tais assimetrias na apropriação social da natureza são geradoras de uma má distribuição ecológica e, portanto, originam conflitos ambientais, na medida em que a utilização de um espaço ambiental ocorra em detrimento do uso que outros segmentos sociais possam fazer de seu território (Martinez-Allier, 1999; 2001; Acselrad, 2004). (Zhouri; Oliveira, 2007, destaques nossos).

Essa abordagem, claramente influenciada pela perspectiva de Acselrad (2004), pela ecologia política de Martinez-Allier (1999) e pela sociologia crítica de Pierre Bourdieu, tem como peculiaridade a aproximação com a bibliografia latino-americana sobre colonialidade na discussão sobre desenvolvimento. Segundo Zhouri e Laschefski (2010), os conflitos ambientais revelam em geral modos diferenciados de existência que expressam a luta por autonomia de grupos que resistem ao modelo de sociedade moderna. Nessa perspectiva, os autores concluem que o questionamento do modelo de desenvolvimento hegemônico frequentemente vinculado à "[...] luta de grupos não inseridos, ou apenas parcialmente inseridos, no sistema urbanoindustrial-capitalista contra a desterritorialização" conduz a refletir sobre o processo de colonialidade do pensamento moderno. A análise dos conflitos ambientais apresenta-se, pois, como um grande desafio, que remete, inclusive, aos fundamentos da produção do conhecimento na academia contemporânea. (Zhouri; Laschefski, 2010, p. 26). 
De forma complementar, destacam-se ainda outros autores que, trabalhando em abordagens também inspiradas pela sociologia crítica, são geralmente utilizados na discussão de questões em relação às quais se tornaram referências, tais como destaca Carneiro (2009), Norma Valencio (conflitos por água, colapso de barragens e crítica às práticas "desapossadoras" empreendidas pela Defesa Civil), Antônio Carlos Diegues (discussão sobre a etnoconservação), Henyo Trindade Barreto Filho (povos indígenas e tradicionais), José Augusto Pádua (história do "pensamento ecopolítico" no Brasil), Franklin Daniel Rothman (conflitos relativos à construção de barragens de usinas hidrelétricas), Ricardo Ferreira Ribeiro (conflitos ambientais no cerrado) e Jean Pierre Leroy (justiça ambiental).

Por outro lado, a partir de uma perspectiva mais identificada com a antropologia, e se aproximando da abordagem de Escobar (2005), Alfredo W. Almeida (Almeida, 1996; 2004; 2009) associa os conflitos ambientais à consolidação de territorialidades específicas, e considera que as mobilizações de conservação ambiental levadas a efeito pelos movimentos sociais na Amazônia significam uma politização do saber sobre a natureza, e por extensão uma politização da própria natureza. Segundo esse autor, dessa forma

Abre-se, de maneira mais formal, um novo capítulo de antagonismos e conflitos socioambientais em que os conhecimentos indígenas e das chamadas "populações tradicionais" começam a se constituir num saber prático em contraponto àquele controlado pelos grandes laboratórios de biotecnologia, pelas empresas farmacêuticas e demais grupos econômicos que detêm o monopólio das patentes, das marcas e dos direitos intelectuais sobre os processos de transformação e processamento dos recursos naturais. (Almeida, 2004, p. 39).

Atrelada a essa análise está a concepção de que a questão ambiental não pode mais ser tratada como uma questão sem sujeito. Para Almeida (2004, p. 44), os sujeitos da questão ambiental que têm se constituído nas 
últimas duas décadas são sujeitos coletivos, que não têm existência individual ou atomizada, mas que se afirmam por meio de sua existência coletiva, politizando nomeações da vida cotidiana e trazendo a complexidade de elementos identitários para o campo de significação da questão ambiental.

Almeida (2004, p. 45) afirma que já não é mais possível dissociar a questão ambiental das associações voluntárias e entidades da sociedade civil - isto é, do socioambientalismo - e que, com tal advento, registrouse uma ruptura profunda com a atitude colonialista homogeneizante, que historicamente apagou as diferenças étnicas e a diversidade cultural. Tal análise é convergente com a proposição de Manuela Carneiro da Cunha e Mauro Almeida (Carneiro da Cunha; Almeida, 2009, p. 279), que formulam a configuração contemporânea da questão ambiental com base na definição de "populações tradicionais" como sujeitos políticos, dispostos a uma negociação: em troca do controle sobre o território, comprometemse a prestar serviços ambientais.

Carneiro da Cunha e Almeida (2009, p. 300), ao narrarem como o estabelecimento da até então inesperada articulação entre a demanda de reforma agrária dos seringueiros e a conservação da floresta amazônica resultou na institucionalização de uma nova modalidade de unidades de conservação (as Reservas Extrativistas), enfatizam a análise do socioambientalismo como o processo de construção de identidades políticas coletivas por grupos que "conquistaram ou estão lutando para conquistar (prática e simbolicamente) uma identidade pública conservacionista". Esse processo se dá, segundo os autores, inserido em um contexto histórico no qual as populações que até recentemente eram consideradas entraves ao desenvolvimento estabelecem novas práticas como possibilidade de permanência em seus territórios.

De forma mais ampla, Alfredo W. Almeida, Manuela Carneiro da Cunha e Mauro Almeida estão vinculados a um grupo de pesquisadores 
que se dedicou a analisar socioantropologicamente as questões ambientais na Amazônia. Neste grupo, destacam-se ainda Edna Castro, cujas pesquisas questionam os projetos de desenvolvimento implantados na Amazônia (Castro; Hébette, 1989; Castro; Pinton, 1997; Castro, 2012), e Marcelo Sampaio Carneiro, este fazendo uma leitura orientada pelas formulações teóricas da nova sociologia econômica e discutindo dispositivos de regulação da indústria florestal na Amazônia. (Carneiro, 2007; 2008).

À guisa de síntese, se pode constatar, portanto, que enquanto Fuks (1996; 2000; 2001) e Lopes $(2004 ;$ 2006) interpretam os conflitos ambientais como atualizações de antigas disputas, mediante a reformulação de linguagens, sentidos e práticas, nas abordagens propostas por Acselrad (2004; 2005) e Zhouri (2004; Zhouri; Laschefski; Pereira, 2005; Zhouri; Laschefski, 2010) e seus grupos de pesquisa o eixo central da formulação dos conflitos ambientais são relações de expropriação e dominação, frequentemente conduzidas por projetos de desenvolvimento. Almeida (1996; 2004; 2009) e Carneiro da Cunha e Almeida (2009), de maneira complementar, elaboram suas interpretações dos conflitos ambientais sob a ênfase dos sujeitos desses conflitos, que constroem identidades reivindicando seus lugares nesses processos. Um esquema que resume esses autores e linhas de pesquisa pode ser visualizado na figura 2 . 


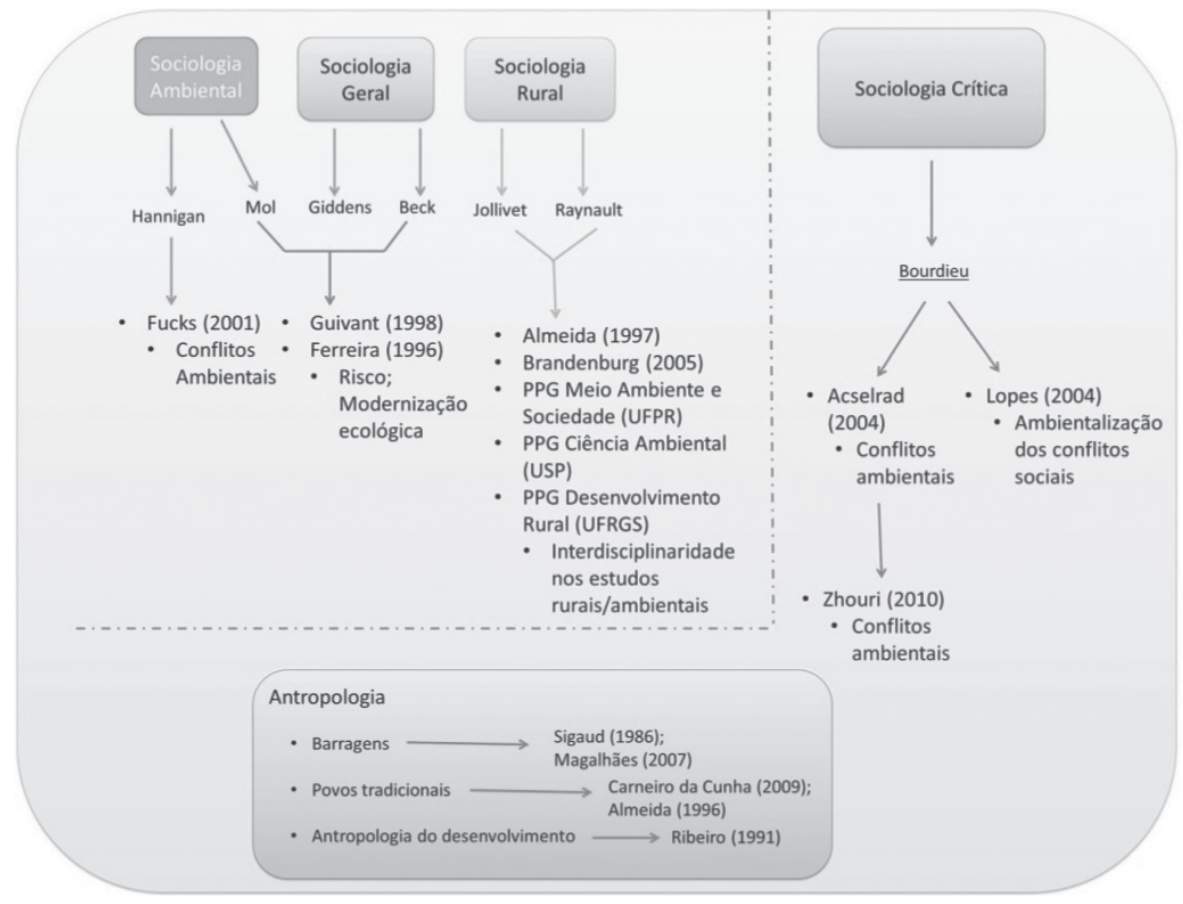

Figura 2. Esquema das abordagens e autores no tema sociologia, ambiente e conflitos ambientais no Brasil.

Nesse sentido, conclui-se que na literatura sobre sociologia e ambiente no Brasil há a delimitação de uma temática particular, denominada conflitos ambientais, a qual se orienta pela discussão dos processos de disputas nos quais o "ambiente" ganha centralidade. Nesses conflitos, mais do que o caráter tecnocientífico das controvérsias, tal qual por autores europeus e norte-americanos, e do que os embates políticos pela definição dos componentes do conflito (sejam definições de biodiversidade ou de entidades outras que os humanos) como na literatura latino-americana, são enfatizadas as relações de expropriação material e violência simbólica 
decorrentes dos processos de desenvolvimento e do papel das comunidades nesses processos.

\section{Conflitos ambientais, conflitos cosmopolíticos?}

Por ser considerado um campo de estudos ainda em formação, considera-se necessário o avanço da reflexão teórica sobre o tema. Alonso e Costa (2002), em artigo intitulado "Por uma sociologia dos conflitos ambientais no Brasil", realizam um balanço da bibliografia até aquele momento sobre conflitos ambientais, a partir do qual consideram que as abordagens identificadas são "elucidativas", entretanto,

[...] fornecem explicações parciais dos conflitos. Uma análise política é incompleta se for unidimensional, seja esta dimensão a economia ou a cultura. Igualmente o é se privilegiar apenas um dentre vários atores em interação, seja a "sociedade civil", seja o Estado. (Alonso; Costa, 2002, p. 125).

Esses autores se posicionam a favor de uma abordagem baseada no modelo da ação política contenciosa (Tilly, 1978; Tarrow, 1994), visando compreender uma sociologia da ação sem abrir mão de um enfoque sociohistórico de origem estruturalista. Assim, seria possível investigar, à luz do esquema teórico da Escola do Processo Político, uma modalidade específica do conflito social: o ambiental. (Alonso; Costa, 2002, p. 127). Contudo, segundo os autores,

Uma interpretação da questão ambiental brasileira desse ponto de vista exige uma pesquisa empírica de fôlego. Por ora, oferecemos apenas uma indicação de quais elementos do contexto brasileiro deveriam ser privilegiados em uma investigação do conflito ambiental à luz dessa perspectiva sociológica. (Alonso; Costa, 2002, p. 127). 
Carneiro (2009), por sua vez, ao realizar um balanço crítico das edições do grupo de trabalho sobre conflitos ambientais nos encontros anuais da Associação Nacional de Pós-Graduação em Ciências Sociais (ANPOCS) como um panorama do cenário dessas pesquisas no Brasil, afirma ser recorrente o questionamento acerca do estatuto teórico do conceito de 'conflitos ambientais', argumentando que uma das tarefas mais importantes é a de avançar na sua elaboração conceitual:

Mais especificamente, percebemos que pairam indefinições cruciais: o "ambiente" que é construído e disputado pelos atores refere-se apenas à "natureza" ou às "condições naturais", entendidas como os elementos e processos comandados pela lógica do mundo físico-biótico que independe da ação humana? Ou esse "ambiente" incorpora também o ambiente construído pela atividade humana, assim como as relações sociais e sistemas simbólicos implicados nessa construção? (Carneiro, 2009, p.18).

O autor se posiciona afirmando que o interesse das ciências sociais na questão ambiental está nas práticas sociais de apropriação do espaço e do que nele se contém: ou seja, o 'ambiente' que interessa às ciências sociais é o ambiente já apropriado pela ação humana, ou seja, o território. (Carneiro, 2009, p. 19).

Este posicionamento do autor de manifestar interesse pelo ambiente socialmente apropriado, em maior ou em menor medida compartilhado por seus pares, aparece em decorrência das abordagens mais utilizadas nas pesquisas analisadas. Segundo Carneiro (2009), Pierre Bourdieu é o autor mais referenciado na bibliografia dos trabalhos apresentados, notando-se uma forte propensão a pensar as situações empíricas a partir do papel nelas desempenhado pelas lutas simbólicas pela imposição das 'divisões de mundo'. Além da influência de Bourdieu, Carneiro acrescenta:

Se as elaborações intelectuais de Bourdieu sobre o poder simbólico são as mais presentes no pano de fundo teórico 
em que se ancoram as análises apresentadas ao GT, as abordagens mais específicas da "questão ambiental" parecem mais fortemente influenciadas pelas formulações de Henri Acselrad acerca da chamada "questão ambiental" como objeto epistêmico. Com efeito, Acselrad é o segundo autor mais referenciado nas bibliografias dos trabalhos apresentados ao GT [...]. A terceira autora mais referenciada pelos trabalhos apresentados ao GT, e que, numa perspectiva semelhante à de Acselrad, tem desenvolvido esforços de elaboração conceitual sobre o domínio de objeto do subcampo das ciências sociais dedicado à discussão da chamada "questão ambiental", é Andréa Zhouri [...]. (Carneiro, 2009, p. 15).

Conforme discutido anteriormente, nas abordagens destes autores os conflitos ambientais são analisados como decorrentes de rupturas de acordos ecológicos devido a incompatibilidades de interpretações simbólicas quanto a unidades territoriais compartilhadas. Assim, se pode afirmar que a concepção subjacente a estas análises não problematiza a separação sociedade-natureza: parte-se do pressuposto de que existe uma natureza, em sua materialidade e ecologia, que é representada diferentemente pelos distintos grupos sociais, o que deflagra, portanto, os conflitos ambientais.

Mas, e se nos conflitos ambientais houver também mais do que isso? E se os grupos em conflito não estiverem de acordo nem sobre as medidas que definem as unidades territoriais, isto é, que separam o que é material e o que é simbólico, o que é natureza do que é sociedade? É nesse sentido que apontam pesquisas realizadas acerca dos conflitos em torno da construção de hidrelétricas na Amazônia, especialmente a Usina Hidrelétrica de Belo Monte, no Pará (Fleury, 2013). Neste conflito, se pode perceber que há diferenças maiores entre os pontos de vista dos diferentes sujeitos do que os estudos de impacto ambiental e as políticas de desenvolvimento podem abarcar. Ao explicitar demandas que alargam as noções convencionais de ambiente e política, considera-se que é em termos cosmopolíticos que este conflito se expressa. No entanto, ainda assim se trata de um con- 
flito ambiental, visto que, neste caso, o ambiente se torna o local de um "equívoco controlado", isto é, o lugar conceitual em que se estabelece uma relação de interpretação diferencial entre termos homônimos com significados distintos entre as perspectivas, de forma que comunica dois mundos e mantém suas diferenças, tornando possível a formulação coelaborada de projetos políticos com espaço para diferentes mundos (Viveiros de Castro, 2009; De la Cadena, 2010). Deste modo, considera-se que reforçar a carga cosmopolítica que a expressão conflito ambiental traz de partida é tirar proveito de sua ambivalência, ou seja, é não perder de vista as possibilidades de equívoco controlado, de se manter a passarela entre as perspectivas sabendo-se que as traduções/traições não apenas são inerentes à comunicação, mas está nelas a possibilidade de coexistência sem síntese, sem que um mundo anule o outro. (Fleury, 2013).

Investigar a emergência e configuração de conflitos ambientais, atentando-se às possibilidades de interpretações das relações sociedadenatureza expressas, é em suma concentrar-se nas interações sociais e naturais articuladas durante os conflitos, visando identificar posições e mapear as alianças e coalizões presentes nos embates políticos, mas também observar elementos cosmológicos, identitários e subjetividades subjacentes à configuração dos conflitos. É, em suma, concentrar-se nas interações sociais, entre humanos e seres outros que humanos articulados durante o conflito, analisando-os em interações e nos movimentos de coprodução nos quais estão envolvidos, salientando as interpretações das relações entre humanos e seres outros que humanos mobilizadas nos conflitos.

Pode-se concluir, pois, que a formulação do ambiente como questão sociológica se trata, não apenas da incorporação de um objeto uno a uma disciplina estabilizada, mas de um processo contínuo de reflexão e reelaboração das cartografias disciplinares, nos quais os próprios termos da análise são colocados em jogo e reformulados de forma a abarcar a complexidade das questões em pauta. 
Lorena Cândido Fleury. Doutora em Sociologia (UFRGS), com Doutorado Sanduíche no Laboratoire Dynamiques Sociales et Recomposition des Espaces - LADYSS em Paris/França. Pesquisadora associada do grupo de pesquisa Tecnologia, Meio Ambiente e Sociedade (TEMAS - www.ufrgs.br/pgdr/temas). Professora adjunta de Sociologia no Instituto de Filosofia e Ciências Humanas da Universidade Federal do Rio Grande do Sul (IFCH/UFRGS). $\gg$ lorenafleury@gmail.com

Jalcione Almeida. Doutor em Sociologia (Université de Paris X), professor associado do Departamento de Sociologia/IFCH-UFRGS, pesquisador permanente nos Programas de Pós-Graduação em Desenvolvimento Rural (PGDR) e Sociologia (PPGS), ambos da Universidade Federal do Rio Grande do Sul (UFRGS), pesquisador $\mathrm{CNPq}$, coordenador do grupo de pesquisa Tecnologia, Meio Ambiente e Sociedade (TEMAS). $\$ jal@ufrgs.br

Adriano Premebida. Doutor em Sociologia (UFRGS), pesquisador e diretor técnico-científico da Fundação de Defesa da Biosfera (FDB), Manaus. Pesquisador associado do grupo de pesquisa Tecnologia, Meio Ambiente e Sociedade (TEMAS). $>$ premebida@hotmail.com

\section{Referências}

1. ACSELRAD, Henri. Apresentação. In: Andréa Zhouri. (Org.). A insustentável leveza da política ambiental. Belo Horizonte: Autêntica, 2005.

2. ACSELRAD, Henri; BEZERRA, Gustavo. Inserção econômica internacional e "resolução negociada" de conflitos ambientais na América Latina. In: ZHOURI, A. LASCHEFSKI, K. (org.). Desenvolvimento e conflitos ambientais. Belo Horizonte: Editora UFMG, 2010. p. 35-62.

3. ACSELRAD, Henri (org.). Conflitos ambientais no Brasil. Rio de Janeiro: Relume Dumará; Fundação Heinrich Böll, 2004.

4. ALMEIDA, Alfredo W. B. de (org.). Conflitos sociais no "Complexo Madeira". Manaus: UEA Edições, 2009.

5. ALMEIDA, Alfredo W. B. de. Refugiados do desenvolvimento: os deslocamentos compulsórios de índios e camponeses e a ideologia da modernização. Travessia. maio/agosto, 1996. p. 30-35.

6. ALMEIDA, Alfredo W. B. de. Terras tradicionalmente ocupadas: processos de territorialização e movimentos sociais. Rio de Janeiro: ANPUR, p. 1-30, 2004.

7. ALMEIDA, Jalcione. Da ideologia do progresso à ideia de desenvolvimento (rural) sustentável. In: ALMEIDA, J.; NAVARRO, Z. (orgs.). Reconstruindo a 
agricultura:ideias e ideais na perspectiva do desenvolvimento rural sustentável. 1ed. Porto Alegre: Editora da Universidade (UFRGS), 1997. p. 33-55.

8. ALMEIDA, Jalcione. O campo da pesquisa e das ações sobre o meio ambiente. Porto Alegre: PGDR/UFRGS, 2004.

9. ALONSO, Ângela; COSTA, Valeriano. Ciências sociais e ambiente no Brasil: um balanço bibliográfico. BIB - Revista Brasileira de Informações Bibliográficas em Ciências Sociais, ANPOCS, n. 53, 1ㅇs., p-35-78. 2002.

10. ALONSO, Ângela; COSTA, Valeriano. Por uma sociologia dos conflitos ambientais no Brasil. Buenos Aires: CLACSO, Consejo Latinoamericano de Ciencias Sociales, 2002. Disponível em: <http://bibliotecavirtual.clacso.org.ar/clacso/ gt/20100930023420/7alonso.pdf>. Acesso em: 12 mai. 2009.

11. AMY, Douglas J. The Politics of Environmental Mediation. New York: Columbia University Press. 1987.

12. BECK, Ulrich. Ecological Politics in an Age of Risk. Cambridge: Polity Press. 1995.

13. BECK, Ulrich. Risk Society: towards a New Modernity. London: Sage, 1992.

14. BINGHAN, Gail. Resolving Environmental Disputes: a Decade of Experience in Resolving Locational Conflict, Lake. New Jersey: R.W. ed.; Center for Urban Policy Research. 1986.

15. BLOOR, David. 'Durkheim and Mauss Revisited: Classification and the Sociology of Knowledge', Studies in the History and Philosophy of Science13, p. 267-97. 1982.

16. BOUDES, Philippe. L'environnement, domaine sociologique. Tese de Doutorado - Université Bordeaux 2 - Mention Sociologique. Avril, 2008.

17. BRANDENBURG, Alfio. Do rural tradicional ao rural socioambiental. In: XII Congresso Brasileiro de Sociologia. Anais..., Belo Horizonte, 2005.

18. BUTTEL, Frederick H.. A sociologia e o meio ambiente: um caminho tortuoso rumo à ecologia humana. Perspectivas, São Paulo, n. 15, p. 69-94. 1992.

19. BUTTEL, Frederick H.; HUMPHREY, Craig R. Sociological Theory and the Natural Environment. In :DUNLAP, Riley E.; MICHELSON, William. (ed). Handbook of Environmental Sociology. Westport, CT: Greenwood Press. p. 33-69. 1982.

20. CALLON, Michel; LASCOUMES, P.; BARTHE, Y. Agir dans un monde incertain. Essai sur la démocratie technique, Paris: Le Seuil, 2001.

21. CALLON, Michel. Some Elements of a Sociology of Translation: Domestication of the Scallops and the Fishermen of St. Brieuc Bay. In: LAW, John (ed). Power, Action and Belief: a New Sociology of Knowledge. London: Routledge \& Kegan Paul. 1986. p. 196-233. 
22. CALLON, Michel; LATOUR, Bruno. Unscrewing the Big Leviathan: how Actors Macro-structure Reality and How Sociologists Help them to do so. In: KNORR-CETINA, K.; CICOUREL, A. V. (eds.). Advances in Social Theory and Methodology: Toward and Integration of Micro-and Macro-Sociologies. Boston: Routledge; Kegan Paul. 1981. p.277-303.

23. CARNEIRO DA CUNHA, Manuela. Cultura com aspas e outros ensaios. São Paulo: CosacNaify, 2009.

24. CARNEIRO DA CUNHA, Manuela; ALMEIDA, Mauro. Populações tradicionais e conservação ambiental. In: CARNEIRO DA CUNHA, M.. Cultura com aspas e outros ensaios. São Paulo: CosacNaify, 2009. p. 277-299.

25. CARNEIRO, Eder J. O GT de conflitos ambientais da ANPOCS (2004-2008): balanço crítico. In: 33ํ Encontro Anual da ANPOCS, Anais... Caxambu, 2009.

26. CARNEIRO, Marcelo S.. A construção social do mercado de madeiras certificadas na Amazônia brasileira: a atuação das ONGs ambientalistas e das empresas pioneiras. Sociedade e Estado, vol. 22, n. 3, p. 681-713. 2007.

27. CARNEIRO, Marcelo S. Crítica social e responsabilização empresarial: análise das estratégias para a legitimação da produção siderúrgica na Amazônia Oriental. Cadernos CRH, vol. 21, n. 53, p. 321-333, 2008.

28. CASTRO, Edna.; HÉBETTE, Jean. (orgs.). Na trilha dos grandes projetos: modernização e conflito na Amazônia. Belém: UFPA/NAEA, 1989.

29. CASTRO, Edna. Amazônia: sociedade, fronteiras e políticas. Cadernos CRH, vol. 25 n. 64 , jan./abr. p. 45-61, 2012.

30. CASTRO, Edna; PINTON, Florence. (orgs.). Faces do trópico úmido: conceitos e questões sobre ambiente e desenvolvimento. Belém: CEJUP/UFPS/NAEA, 1997.

31. CATTON, William R.; DUNLAP, Riley E. A New Ecological Paradigm for PostExuberant Sociology. American Behavioral Scientist, vol. 24, n. 1, set./oct., p. 15-47, 1980.

32. CHATEAURAYNAUD, Francis; TORNY, Didier. Les sombres précurseurs: une sociologie pragmatique de l'alerte et du risque. Paris: Ed. de L'EHESS. 1999.

33. CHATEAURAYNAUD, Francis; TORNY, Didier. Mobiliser autour d'un risque: des lanceurs aux porteurs d'alerte. 2005.

34. COLLINS, H. M. Changing Order: Replication and Induction in Scientific Practice. London: Sage. 1985.

35. DE LA CADENA, Marisol. Indigenous Cosmopolitics in the Andes: Conceptual Reflections beyond "Politics". Cultural Anthropology, vol. 25, n. 2, p. 334-370. 2010. 
36. ESCOBAR, Arturo. Mas allá del Tercer Mundo. Globalización y Diferencia. Bogotá: Instituto Colombiano de Antropología e Historia. 1998.

37. ESCOBAR, Arturo; PARDO, Maurício. Movimentos sociais e biodiversidade no pacífico colombiano. In: SANTOS, Boaventura de Sousa (org.). Semear outras soluções: os caminhos da biodiversidade e dos conhecimentos rivais. Rio de Janeiro: Civilização Brasileira, 2005. p. 341-374.

38. FERREIRA, Leila da C. Conflitos sociais e uso de recursos naturais: breves comentários sobre modelos teóricos e linhas de pesquisa. Política \& Sociedade, n. 7, p. 105-118, out. 2005.

39. FLEURY, Lorena C. Conflito ambiental e cosmopolíticas na Amazônia brasileira: a construção da Usina Hidrelétrica de Belo Monte em perspectiva. Tese (Doutorado em Sociologia). Programa de Pós-Graduação em Sociologia, Universidade Federal do Rio Grande do Sul (PPGS/UFRGS). 2013.

40. FUKS, Mario. Conflitos ambientais no Rio de Janeiro: ação e debate nas arenas públicas. Rio de Janeiro: Editora da UFRJ, 2001.

41. FUKS, Mario. Definição de agenda, debate público e problemas sociais: uma perspectiva argumentativa da dinâmica do conflito social. In: XXIV Encontro Anual da ANPOCS. Anais.... Petrópolis (RJ). out/2000.

42. GERHARDT, Cleyton H.;ALMEIDA, Jalcione. A dialética dos campos sociais na interpretação da problemática ambiental: uma análise crítica a partir de diferentes leituras sobre os problemas ambientais. Ambiente e Sociedade, vol. 3, n. 2, p. 53-83, 2005.

43. GIDDENS, Anthony. Sociologia. 2. ed. Madrid: Alianza Editorial, 1995.

44. GUIVANT, Júlia S. Conflitos e negociações nas políticas de controle ambiental: o caso da suinocultura em Santa Catarina. Ambiente e Sociedade, n. 2. p. 101-23.1998.

45. HANNIGAN, John A. Sociologia ambiental: a formação de uma perspectiva social. Lisboa: Piaget, 1997.

46. HARAWAY, Donna. Simians, Cyborgs, and Women: the Reinvention of Nature. New York: Routledge, 1991.

47. HILGARTNER, Stephen; BOSK, Charles L. The Rise and Fall of Social Problems: a Public Arenas Model. American Journal of Sociology, vol. 94, n. 1, p. 53-78, 1988.

48. JASANOFF, Sheila. States of Knowledge: the Co-Production of Science and Social Order. Routledge: London and New York, 2006. 
49. JOLLIVET, Marcel. Sciences de la nature, science de la société, les passeurs de frontiéres. Paris: Centre National de la Recherche Scientifique (CNRS) Editions, 1992.

50. JOLLIVET, Marcel; PAVÉ, Alain. L'environnement: un champ de recherche en formation, Natures, Sciences, Sociétés, vol. 1, n. 1, p. 6-24, 1993.

51. KALAORA, Bernard, Le musée vert, radiographie du loisir en forêt. Paris: L'Harmattan, [1978] 1993.

52. LAMINE, Claire; TÉTART, Gilles; CHATEAURAYNAUD, Francis. Le bio comme reconfigurateur des controverses sur les pesticides et les OGM (1995-2008). Colloque de la SFER, mars 2010.

53. LATOUR, Bruno. Jamais fomos modernos. Rio de Janeiro: Editora 34, 1994. 54. LATOUR, Bruno. Petites leçons de sociologie des sciences. Paris: La Découverte, Point Seuil, 2003.

55. LATOUR, Bruno. Quel cosmos? Quelles cosmopolitiques? In: LOLIVE, Jacques; SOUBEYRAN, Olivier. L'emergence des cosmopolitiques. Paris: La Découverte. 2007.

56. LATOUR, Bruno. Reassembling the Social: an Introduction to Actor-NetworkTheory. New York: Oxford University Press, 2005.

57. LATOUR, Bruno; SCHWARTZ, Cécile; CHARVOLIN, Florian. Crises dos meios ambientes: desafios às ciências humanas. In: ARAÚJO, Hermetes R. de (Org.). Tecnociência e cultura: ensaios sobre o tempo presente. São Paulo: Estação Liberdade,. p. 91-126, 1998.

58. LIBISZEWSKI, Stephan. What is an Environmental Conflict? Meeting of the Environment and Conflicts Project. Zürich, april 1993.

59. LOPES, José S. L. (coord.); ANTONAZ, Diana; PRADO, Rosane; SILVA, Gláucia (orgs.). A ambientalização dos conflitos sociais: participação e controle público da poluição industrial. Rio de Janeiro: RelumeDumará, 2004.

60. LOPES, José S. L.. Sobre processos de "ambientalização" dos conflitos e sobre dilemas da participação. Horizontes Antropológicos, Porto Alegre, ano 12, n. 25, p. 31-64, jan./jun. 2006.

61. MAGALHÃES, Sônia. Lamento e dor: uma análise sócio-antropológica do deslocamento compulsório provocado pela construção de barragens. Tese de doutorado. Programa de Pós-Graduação em Ciências Sociais (UFPA) e École Doctorale Vivant et Sociétés (Paris XIII). Belém: UFPA, 2007.

62. MARTÍNEZ-ALIER, Joan. Introducción a la economía ecológica. Cuadernos de Medio Ambiente. Rubens: Barcelona, 1999. 
63. MATHIEU, Nicole; JOLLIVET, Marcel (dir.). Du rural à I'environnement: la question de la nature aujourd'hui, Paris: ARF - L'Harmattan, 1989.

64. MATTEDI, Marcos A. Dilemas da abordagem sociológica da problemática ambiental: considerações epistemológica, metodológica e normativa sobre a guinada ambiental na sociologia. In: XXIV Congresso Latino-americano de Sociologia, Anais... Arequipa, 2003.

65. MOL, Arthur.P. J.; SPAARGAREN, Gert. Environment, Modernity, and the RiskSociety: the Apocalyptic Horizon of Environmental Reform, International Sociology, vol. 8, n..4, p. 431-59, 1993.

66. O'CONNOR, John. Is Sustainable Capitalism Possible? In: O'CONNOR, Martin (ed.), Is Capitalism Sustainable? New York: Guilford, 1994.

67. OZAWA, Connie P. Science in Environmental Conflicts. Sociological Perspectives, vol. 39, n. 2. p. 219-230. 1996.

68. RANNIKKO, Pertti. Local Environmental Conflicts and Change in Environmental Consciousness. Acta Sociologica, n.39, p. 57-72 1996.

69. RAYNAULT, Claude. Meio ambiente e desenvolvimento: construindo um novo campo do saber a partir da perspectiva interdisciplinar. Desenvolvimento e Meio Ambiente, n. 10, p. 21-32, jul./dez. 2004.

70. RIBEIRO, Gustavo L. Empresas transnacionais: um grande projeto por dentro. Rio de Janeiro/São Paulo: ANPOCS/ Marco Zero. 1991.

71. SCHNAIBERG, Allan. The Environment. New York: Oxford Univ. Press. 1980.

72. SCOTT, James. Seeing like a State: how Certain Schemes to Improve the Human Condition have Failed. New Haven and London: Yale University Press. 1998.

73. SHAPIN, Steven.;SCHAFFER, Simon. Leviathan and the Air-Pump: Hobbes, Boyle, and the Experimental Life. Princeton: Princeton University Press. 1985.

74. STENGERS, Isabelle. Cosmopolitiques I. Paris : Éditions la Découverte, 2003a (1997).

75. STENGERS, Isabelle. Cosmopolitiques II. Paris : Éditions la Découverte, 2003b (1997).

76. TARROW, Sidney . Power in Movement. Cambridge: Cambridge UniversityPress, 1994.

77. THOMAS, Keith. O homem e o mundo natural. São Paulo: Companhia das Letras. 1988.

78. TILLY, Charles. From Mobilization to Revolution. Michigan: Reading M.A. Addison-Wesley. 1978. 
79. ULLOA, Astrid. A ecogovernamentalidade e suas contradições. Ecopolítica, vol.1, p. 26-42, 2011.

80. ULLOA, Astrid. La construcción del nativo ecológico. Instituto Colombiano de Antropología e Historia -ICANH- COLCIENCIAS, Bogotá, 2004.

81. VIEGAS, Rodrigo N.. As resoluções de conflitos ambientais no cenário brasileiro. In: 33ํㅡㄹ Encontro Anual da ANPOCS, Anais... Caxambu, 2009.

82. VIEIRA, Paulo F. A problemática ambiental e as ciências sociais no Brasil: 1980-1990. BIB - Boletim Informativo Bibliográfico. São Paulo, Associação Nacional de Pós-Graduação e Pesquisa em Ciências Sociais, n. 33. 1992.

83. VIVEIROS DE CASTRO, Eduardo. Métaphysiques cannibales, Paris: PUF (Métaphysiques), 2009.

84. ZHOURI, Andréa. A Re-volta da ecologia política: conflitos ambientais no Brasil. Ambiente e Sociedade, Campinas, vol. 7, n. 2, p. 211-213, 2004.

85. ZHOURI, Andrea; LASCHEFSKI, Klemens (orgs.). Desenvolvimento e conflitos ambientais. Belo Horizonte: Ed. UFMG, 2010.

86. ZHOURI, Andréa; LASCHEFSKI, Klemens; PEREIRA, Doralice (orgs.). A insustentável leveza da política ambiental. Belo Horizonte: Ed. Autêntica, 2005.

87. ZHOURI, Andréa; OLIVEIRA, Rachel. Desenvolvimento, conflitos sociais e violência no Brasil rural: o caso das usinas hidrelétricas. Ambiente e Sociedade, vol. 10, n. 2, p. 119-135, 2007.

Recebido em: 11/10/2013

Aceite final: 04/12/2013 